\title{
DERECHOS SOCIALES Y PROHIBICIÓN DE REGRESIVIDAD: EL CASO ISSSTE Y SU VOTO DE MINORÍA ${ }^{1}$
}

\author{
Fernando SILVA GARCÍA \\ Emmanuel ROSALES GUERRERO
}

\section{INTRODUCCIÓN}

Tanto la doctrina académica ${ }^{2}$ como la jurisprudencial ${ }^{3}$ han reconocido la prohibición de regresividad de los derechos sociales. En términos muy

1 El 19 de junio de 2008, el Pleno de la Suprema Corte de Justicia de la Nación resolvió los amparos en revisión 218/2008, 219/2008, 220/2008, 221/2008, 229/2008, 235/2008, 236/2008, 237/2008, 241/2008 y 252/2008 interpuestos en contra de las sentencias dictadas por el juez primero de distrito auxiliar con competencia y jurisdicción en toda la República y residencia en el Distrito Federal, en que se impugnó la nueva Ley del ISSSTE y el artículo 7o. de la Ley del Diario Oficial de la Federación y Gacetas Gubernamentales.

2 López Guerra, Luis y Esteban, Jorge de, El régimen constitucional español, Barcelona, Labor, 1980, t. I; véase, Cascajo Castro, José Luis, La tutela constitucional de los derechos sociales, Madrid, CEC, 1988; Courtis, Christian, Ni un paso atrás. La prohibición de regresividad en materia de derechos sociales, Ediciones Del Puerto, 2006; Pisarello, Gerardo, Los derechos sociales y sus garantías. Elementos para una reconstrucción, Madrid, Trotta, 2007; Abramovich, Víctor et al., Los derechos sociales como derechos exigibles, Madrid, Trotta, 2002.

3 Por ejemplo, la Corte Constitucional de Colombia, en la sentencia C-177/05 dictada con motivo de la presentación de la demanda de inconstitucionalidad contra el artículo 16 del código sustantivo laboral, sentó una serie de pautas tendentes a desarrollar el contenido del principio de progresividad y no regresividad; asimismo, estableció una serie de limitaciones al legislador. Sostuvo que: el mandato de progresividad implica que una vez alcanzado un determinado nivel de protección, la amplia configuración del legislador en materia de derechos sociales se ve restringida al menos en un aspecto. Todo retroceso frente al nivel de protección alcanzado es constitucionalmente problemático puesto que 
generales, dicha norma "constitucional" implica que las leyes no deben empeorar la situación de regulación del derecho vigente, desde el punto de vista del alcance y amplitud del goce de los derechos sociales. En todo caso, la regresividad de una norma legal en materia de seguridad social determina una presunción de invalidez o de inconstitucionalidad, transfiriendo al Estado la carga de argumentar a favor de su razonabilidad, idoneidad, necesidad y/o proporcionalidad (la existencia de un interés imperioso que justifique la medida adoptada), lo que supone la demostración de: 1) la existencia de un interés estatal permisible; 2) el carácter imperioso de la medida y 3) la inexistencia de cursos de acción alternativos menos restrictivos de los derechos sociales en cuestión.

El 31 de marzo de 2007 se publicó la "nueva" Ley del Instituto de Seguridad y Servicios Sociales de los Trabajadores del Estado (LISSSTE), la cual modificó todo el régimen de derechos de seguridad social con la finalidad de lograr su "viabilidad financiera". Dicha legislación produjo la disminución de toda una serie de prestaciones sociales, sin dejar abierta la opción de permanecer en el sistema anterior, lo que generó que decenas de miles de trabajadores cuestionaran la constitucionalidad de la Ley ante los tribunales de amparo. Como veremos, el Pleno de la SCJN, por mayoría de votos, declaró la constitucionalidad de la ley. Frente a dicha decisión, la posición minoritaria desprendió de la Constitución de 1917, en relación con diversos instrumentos internacionales sobre derechos humanos, la existencia del principio de no regresividad de los derechos sociales en beneficio de los trabajadores. La importancia de dicho asunto radica en que la SCJN se enfrentó con el problema de determinar

contradice al mandato de progresividad. Ahora bien, como los Estados pueden enfrentar dificultades que pueden hacer imposible el mantenimiento de un grado de protección alcanzado, es obvio que la prohibición no puede ser absoluta sino que debe ser entendida como una prohibición prima facie. Un retroceso debe presumirse en principio inconstitucional, pero puede ser justificable y por ello, estar sometido a un control judicial más severo. En tal sentido, en la causa Rosa Delia Pico Delgado c/ la Secretaría Municipal de Salud de Barrancabermeja (T-884/03), la Corte colombiana estableció que: la exclusión de los derechos sociales del amparo constitucional no es de ningún modo absoluta puesto que en eventos concretos es posible que de la satisfacción de aquéllos dependa la protección y el goce efectivo de los derechos fundamentales, relación de subordinación que se acredita a través de la comprobación de determinadas condiciones fácticas en cada caso. Una vez realizada esa labor probatoria por el juez constitucional está facultado para emitir órdenes de amparo tendentes a restituir al afectado en el ejercicio del derecho a la prestación y con ello proteger el derecho fundamental vulnerado. 
qué límites tiene la política frente a los derechos sociales de los trabajadores y/o hasta qué punto nuestro sistema jurídico autoriza la existencia de leyes regresivas que disminuyen prestaciones de seguridad social. En las siguientes líneas desarrollaremos con mayor precisión dichas cuestiones.

\section{DERECHOS FUndAMENTALES. PERSPECTIVA SOCIAL E IGUALITARIA}

En términos generales, es posible afirmar que la prohibición de regresividad de los derechos sociales constituye una de las diversas manifestaciones de la perspectiva social e igualitaria de los derechos fundamentales. Parte de la doctrina ha apuntado que los derechos fundamentales son reactivos a las situaciones históricas, políticas, sociales, culturales y económicas en el que se desenvuelve su ejercicio. ${ }^{4} \mathrm{~A}$ partir de esa premisa y considerando el manifiesto estado de crisis económica en el mundo, se ha subrayado la necesidad de que la esencia de los derechos fundamenta-

4 Los derechos son reactivos a las nuevas y distintas formas que los amenazan (Convención sobre Bioética y el derecho al agua, por ejemplo). "Las pretensiones morales que fundamentan cada derecho, tienen un carácter histórico que aparece cuando surge la necesidad, o cuando el progreso técnico lo permite...". Peces-Barba Martínez, Gregorio, "La universalidad de los derechos humanos", en Nieto Navia, Rafael (ed.), La Corte y el sistema interamericanos de derechos humanos, San José, Corte IDH, 1994, p. 410. Piénsese también en la respuesta jurisdiccional de la Corte Suprema de Estados Unidos de América a la política llamada New Deal de Roosvelt como reacción a la crisis económica derivada del periodo entre guerras. También podría señalarse como ejemplo el caso Brown de la Corte Suprema de los Estados Unidos de América, que termina con la "legalidad" de la segregación racial en ese país, entre otros factores, como respuesta congruente a la adopción de la bandera de la libertad e igualdad acogida por los Estados Unidos al intervenir en la segunda guerra mundial; Ackerman, Bruce, We the People 1. Foundations, Reino Unido, The Belknap Press of Harvard University Press, 1991, pp. 130-137. Desde luego que es citable como ejemplo el emergente derecho al medio ambiente adecuado. Véase Socorrer al planeta, número 25, noviembre, 1997; Le Monde Diplomatique. Los 100 Editoriales, edición española, noviembre de 1995. De allí el surgimiento de nuevos retos en el ámbito de los derechos fundamentales tratándose de los riesgos para las libertades derivados de la ingeniería genética, la contaminación electromagnética, el cambio climático, etcétera. Véase Doménech Pascual, Gabriel, Derechos fundamentales y riesgos tecnológicos. El derecho del ciudadano a ser protegido por los poderes públicos, Madrid, CEPC, 2006; González Valenzuela, Juliana (coord.), Dilemas de bioética, México, Fondo de Cultura Económica, 2007. 
les se entienda como la tutela de los más débiles, ${ }^{5}$ lo cual tiende a referirse a la protección de los más vulnerables, en un sentido social, cultural y económico. Desde esa perspectiva, se ha afirmado que la fundamentalidad axiológica de todos los derechos remite al principio de igualdad. ${ }^{6}$ Es decir, se ha afirmado que aquello que convierte en fundamental un derecho en términos valorativos y teóricos es su estructura igualitaria, o sea, el hecho de proteger intereses o necesidades generalizables o inclusivos, y por ello indisponibles e inalienables. Eso sería, precisamente lo que distinguiría un derecho fundamental de un privilegio, cuya estructura es, por definición, tendencialmente selectiva, excluyente y alienable. ${ }^{7}$ De allí que los derechos fundamentales sean, tanto límites al ejercicio del poder político, como fines directivos de acción positiva a cargo de los poderes públicos, ${ }^{8}$ para remover los obstáculos de orden económico, social y cultural, que impiden la plena libertad e igualdad entre los seres humanos.

Las dificultades económicas que trajo el Estado neoliberal han llevado a la doctrina académica a intentar reformular algunos elementos de la

5 Entre los grupos vulnerables se suelen mencionar: la madre soltera, menores y adolescentes en situación de riesgo social, menores trabajadores, personas de tercera edad, personas discapacitadas, población rural, mujeres embarazadas y en estado de lactancia, desempleados, excluidos de la seguridad social, mujeres discriminadas, pueblos indígenas. Véase González Galván, Jorge Alberto et al., "La pluralidad de los grupos vulnerables: un enfoque interdisciplinario" y Carmona Tinoco, Jorge Ulises, "Panorama y propuestas sobre la aplicabilidad de los derechos fundamentales de los grupos en situación vulnerable", ambos en Valadés, Diego y Gutiérrez Rivas, Rodrigo (coords.), Memoria del IV Congreso Nacional de Derecho Constitucional, México, UNAM, Instituto de Investigaciones Jurídicas, 2001, t. III: Derechos humanos, pp. 225-243 y 193-207, respectivamente.

6 Dworkin, Ronald, Virtud soberana. La teoría y la práctica de la igualdad, Barcelona, Paidós, 2003.

7 Véase Pisarello, Gerardo, Los derechos sociales..., op. cit., nota 2, pp. 37 y 38.

8 Pérez Luño, Antonio E., Los derechos fundamentales, 7a. ed., Madrid, Tecnos, 1998, p. 21. Por ejemplo, la Corte Suprema de Estados Unidos, en la sentencia Westvirginia State Board Of Education vs. Barnette, 1943, estableció que no resultaba fácil trasladar la Declaración de Derechos, en tanto que elemento estructural de la sociedad del siglo XVIII, a las limitaciones de derechos en la Norteamérica del siglo XX. Aquellos principios se originaron en un momento en el que se concebía al individuo como el centro de la sociedad, en el que se afirmaba que a su libertad se llegaba por la mera abstención de los gobiernos, y en el que éstos tenían poca capacidad de control o supervisión de los asuntos de los ciudadanos. Ahora debemos trasladar estos principios a una situación en la que el laissez faire ya no se aplica - por lo menos en lo económico- y en la que el progreso social se alcanza a costa de un mayor control gubernamental. 
teoría de los derechos fundamentales. ${ }^{9}$ En ese sentido, se ha apuntado que las nuevas formulaciones teóricas requieren tomar en cuenta un entendimiento de los derechos fundamentales en una inescindible correlación con los principios que consagran la forma de Estado y que definen el sistema económico, ${ }^{10}$ pues únicamente de esa forma pueden suponer medios adecuados para los particulares frente a sus posibles amenazas, en razón a la existencia de grupos nacionales y multinacionales detentadores de una hegemonía fáctica sobre el resto de los individuos. ${ }^{11}$

Esas aportaciones terminarían por definir a los derechos fundamentales desde una idea equitativa y justa, como aquellos de los que deben gozar todos los individuos sin discriminaciones derivadas de la clase eco-

9 La mundialización financiera ha creado de esta forma su propio Estado: un Estado supranacional, que dispone de sus aparatos, de redes de influencia y de sus propios medios de acción. Se trata de la constelación formada por el Fondo Monetario Internacional (FMI), el Banco Mundial, la Organización para la Cooperación y el Desarrollo Económico (OCDE) y la Organización Mundial del Comercio (OMC). Una vez que se propone intervenir, la OMC puede declarar a las legislaciones nacionales en materia de derecho laboral, de medio ambiente o de salud "contrarias a la libertad de comercio" y pedir su derogación. Incluso se ha señalado que la libertad total de circulación de capitales desestabiliza a la democracia. Por ello, se ha considerado sano poner en marcha mecanismos disuasorios. Uno de ellos es la tasa Tobin, que toma su nombre del Premio Nobel norteamericano de economía, que la propuso en 1972. Se trata de gravar, de forma módica, todas las transacciones sobre los mercados de cambios para estabilizarlos y, al mismo tiempo, para procurar ingresos a la comunidad internacional. Con un nivel del $0.1 \%$, la tasa Tobin lograría anualmente unos 166 mil millones de dólares, dos veces más que la suma anual necesaria para erradicar la pobreza extremada de aquí al comienzo del próximo siglo. Para impulsar la puesta en marcha efectiva de este impuesto mundial por la solidaridad. Desarmar a los mercados, número 26-noviembre, 1997; Le Monde Diplomatique. Los 100 Editoriales, cit., nota 4. Algunas empresas han alcanzado dimensiones titánicas. $\mathrm{Su}$ volumen de negocios es a veces, superior al Producto Nacional Bruto (PNB) de numerosos países desarrollados, empresas gigantes, Estados diminutos, número 32-junio y julio, 1998; Le Monde Diplomatique. Los 100 Editoriales, cit., nota 4.

10 Sobre el problema de la vinculación de los derechos prestacionales a aspectos financieros y la intervención de jueces en ese ámbito. Alexy, Robert. Teoría de los derechos fundamentales, trad. de Ernesto Garzón ValdésMadrid, CEC, 1987, pp. 425-435.

11 Los tres primeros fondos de pensiones americanos - los Big Three de hoy -, Fidelity Investments, Vanguard Group y Capital Researche and Management controlan 500 mil millones de dólares. Los nuevos amos del mundo. Número 2-diciembre, 1995. Le Monde Diplomatique. Los 100 Editoriales, cit., nota 4. En relación con la enorme influencia del sector privado sobre el Estado mexicano, véase Cosío Villegas, Daniel, El sistema político mexicano. Las posibilidades del cambio, México, Joaquín Mortiz, 1975, pp. 34, 72 y 73. 
nómica y social, del sexo, de la religión, la raza, la condición de salud, etcétera. A partir de ello, se pondría énfasis en la llamada democracia social, que permite la toma de decisiones y el reconocimiento de una garantía de condiciones mínimas también en el ámbito económico, que implica la apertura de nuevos espacios para el ejercicio de la soberanía popular y que hace posible una más equitativa distribución de la riqueza ${ }^{12} \mathrm{y}$, en última instancia, una mayor igualdad entre los hombres. Todo ello, principalmente, a través del reconocimiento de la exigibilidad o justiciabilidad directa $^{13} \mathrm{y}$, por ende, una mayor eficacia, de los derechos fundamentales de tipo social, económico y cultural. ${ }^{14}$

En la jurisprudencia de los distintos tribunales constitucionales en el mundo está presente, desde luego, esa perspectiva social de los derechos fundamentales. ${ }^{15}$ Recientemente, la propia SCJN ha incorporado esa vi-

12 Según Naciones Unidas, alcanzar la satisfacción universal de las necesidades en materia sanitaria no costaría más de 13 mil millones de dólares, es decir, apenas lo que los habitantes de Estados Unidos y la Unión Europea invierten cada año en el consumo de perfumes. Estrategias sobre el hambre. Número 37-noviembre, 1998. Le Monde Diplomatique. Los 100 Editoriales, cit., nota 4. En la era del neoliberalismo, ejercer como superpotencia no garantiza en absoluto a todos los ciudadanos un nivel satisfactorio de desarrollo humano. En Estados Unidos hay 32 millones de personas cuya esperanza de vida es inferior a los sesenta años, 40 millones sin cobertura médica, 45 millones que viven por debajo del umbral de la pobreza y 52 millones de analfabetos. En el seno de la opulenta Unión Europea, en el momento del nacimiento del euro, hay 50 millones de pobres y 18 millones de parados. Nuevo siglo. número 39-enero, 1999; Le Monde Diplomatique. Los 100 Editoriales, cit., nota 4.

13 Las razones de la justiciabilidad de los derechos económicos, sociales y culturales, Abramovich, Víctor et al., Los derechos sociales..., op. cit., nota 2.

14 Algunas propuestas de justiciabilidad, que apuntan hacia un diálogo entre los jueces y el Parlamento, en Tushnet, Mark, Weak Courts, Strong Rights. Judicial Review and Social Welfare Rights in Comparative Constitucional Law, Estados Unidos de América, Princeton University Press, 2008.

15 Tribunal Europeo de Derechos Humanos Plattform Arzte Für das Leben c. Austria 21-junio-1988. Corte Suprema de Estados Unidos de América, Westvirginia State Board of Education c. Barnette, 1943; Corte Suprema Argentina, Asociación Benghalensis, 2000; Tribunal Federal Suizo, V. c. Einwohrnergemeine $X$ und Regiesrunsgrat des Kantons Bern, 2005; Corte Constitucional Colombiana CCC T-1150, 2000; Cámara de Lores en Reino Unido R. vs Secretary of State for Home Department ex parte Adam, 2005. La Constitución de Costa Rica establece en su artículo 78 que el gasto público en educación estatal, incluida la superior, no será inferior al 6\% anual del PIB. 
sión de los derechos fundamentales en su jurisprudencia constitucional. ${ }^{16}$ Sin embargo, al parecer, en el asunto que es materia de nuestro comentario jurisprudencial, la expuesta dimensión social e igualitaria de los derechos sociales no tuvo la proyección suficiente.

\section{El CARÁCTER REGRESIVO DE LA NUEVA LEY DEL ISSSTE}

Al parecer, la nueva ley del ISSSTE es regresiva, con independencia de que dicho carácter haya sido o no justificado constitucionalmente por el legislador.

De entrada, si bien es verdad que conforme al artículo cuarto transitorio de la Ley, a los trabajadores que se encontraban cotizando al régimen del Instituto a la fecha de entrada en vigor de la Ley, se les reconocen los periodos cotizados con anterioridad, lo cierto es que, objetivamente es éste el único derecho que se otorga a los trabajadores que al 1o. de abril están en trabajo activo cotizando al Instituto. En cambio, quienes tengan licencia sin goce de sueldo y no hubieran estado cotizando a partir de esa fecha, quedan colocados en una laguna legislativa y pueden perder —además de todo lo que pierden los trabajadores que sí están cotizando al 1o. de abril- hasta las cotizaciones anteriores.

Asimismo, en el artículo quinto transitorio de la Ley, se señala que los trabajadores tienen derecho a optar por el régimen que se establece en el artículo décimo transitorio, o por la acreditación de bonos de pensión

16 DERECHO AL MÍNIMO VITAL EN EL ORDEN CONSTITUCIONAL MEXICANO, registro 172,545 , tesis aislada, constitucional, novena época, primera sala, Semanario Judicial de la Federación y su Gaceta, XXV, mayo de 2007, tesis 1a. XCVII/2007, p. 793, amparo en revisión 1780/2006; Lempira Omar Sánchez Vizuet. 31 de enero de 2007. Cinco votos, ponente: José Ramón Cossío Díaz. Secretario: Juan Carlos Roa Jacobo. Véase COMERCIO, DERECHO DEL ESTADO PARA ESTABLECER LIMITACIONES A LA LIBRE CONCURRENCIA, registro 335,243, tesis aislada, administrativa, quinta época, segunda sala, Semanario Judicial de la Federación, XLV, tesis, p. 1978, t. XLV, p. 6284. TrABAJO, LIBERTAD DE, registro 381,543, tesis aislada, laboral, quinta época, cuarta sala, Semanario Judicial de la Federación, t. XLVIII, tesis, p. 274. SALUD. EL DERECHO A SU PROTECCIÓN, QUE COMO GARANTÍA INDIVIDUAL CONSAGRA EL ARTÍCULO 4o. CONSTITUCIONAL, COMPRENDE LA RECEPCIÓN DE MEDICAMENTOS BÁSICOS PARA EL TRATAMIENTO DE LAS ENFERMEDADES Y SU SUMINISTRO POR LAS DEPENDENCIAS Y ENTIDADES QUE PRESTAN LOS SERVICIOS RESPECTIVOS, registro, 192,160, tesis aislada, constitucional, novena época, pleno, Semanario Judicial de la Federación y su Gaceta, XI, marzo de 2000, tesis P. XIX/2000, p. 112. 
ISSSTE en sus cuentas individuales; siendo que ese cambio de sistema que se otorga a los trabajadores en activo no implica adoptar un nuevo regimen o conservarse en el anterior. Lo que en realidad se da a escoger a los trabajadores son dos regímenes nuevos y distintos del anterior, pero no el derecho a continuar con el régimen al cual estaban sujetos durante su trayectoria laboral, con lo que se compromete seriamente la prohibición de regresividad, al menos respecto de los trabajadores que ya habían cotizado en cierta medida al régimen anterior. Pero además ese derecho de elección u opción se encuentra limitado con lo previsto en el último párrafo del artículo séptimo transitorio que obliga al trabajador a manifestar por escrito, en un formato que se publicará en el Diario Oficial de la Federación en alguna fecha no especificada entre el 1o. de enero y el 30 de junio de 2008 (prorrogado al 30 de octubre de 2008), ya que de no manifestar expresamente su elección, se entenderá que tácitamente se optó por la acreditación de bonos de pensión del ISSSTE, con lo cual se afecta seriamente el aspecto del consentimiento pues el mismo no puede asegurarse que haya sido en términos óptimos, o sea, de manera, libre, consciente, querida y con ausencia de vicios de la voluntad (dolo, error, lesión, mala, fe o violencia).

Otro aspecto a reflexionar, de naturaleza regresiva, lo es el artículo noveno transitorio (último párrafo) donde se establece que para determinar el monto de los bonos de pensión del ISSSTE en cada caso particular, se deberá multiplicar el numeral que corresponda en la tabla a los años de cotización y edad del trabajador, por el sueldo básico, elevado al año y expresado en unidades de inversión, que estuviere percibiendo el trabajador al último día del año anterior a que entre en vigor esta Ley. En este aspecto, además de que por sus características puede llegar a ser subjetivo, quienes escogan la opción de los bonos de pensión del ISSSTE, deberán tomar en consideración, en primer lugar, que dicho bono será calculado tomando en cuenta el sueldo básico de la nueva Ley, que difiere mucho del sueldo básico de la Ley anterior. La Ley vigente con anterioridad, en su artículo 15 define el sueldo básico como "la suma del sueldo presupuestal, la compensación y el sobresueldo”, y la Ley nueva, en su artículo 17, lo define como "el sueldo del tabulador regional que para cada puesto se haya señalado", lo que significa que la base para determinar cuantías de pensión y valor del bono de pensión del ISSSTE está disminuida en la nueva Ley. Es pertinente adelantar que 
este aspecto del sueldo que se toma en cuenta para efectos del bono, fue objeto de una interpretación conforme con la Constitución por parte de la SCJN en las sentencias donde se estudió el caso que se comenta, y se adelanta que se dijo que lo razonable en este caso, congruentemente con la jurisprudencia 2a./J 40/2004, ${ }^{17}$ era tomar como referencia no el salario que señala la nueva Ley, sino el básico o tabular que comprende, considerado en el artículo 17 de la Ley del ISSSTE, al sueldo tabular regional establecido en la Ley Federal de los Trabajadores al Servicio del Estado que incluye los conceptos de sueldo, sobresueldo y compensación, entendida esta última como la cantidad adicional que se otorgaba discrecionalmente en cuanto a su monto y duración por servicios especiales; y también cabe destacar que la anterior intepretación matiza el contenido de la Ley, sin embargo, hay que recordar que lo que en este apartado se analiza es verificar si el contenido de la nueva Ley es regresivo o no, y desde esta perspectiva claramente sí es regresiva.

En segundo lugar, también debe considerarse que el valor de los bonos de pensión del ISSSTE en unidades de inversión, no va a ser el valor de estas unidades a la fecha en que se defina el bono que se va a depositar en la cuenta individual de cada trabajador, sino el valor que tengan las unidades de inversión al 31 de diciembre del año 2007, como tampoco será el último sueldo recibido por el trabajador, sino el que se tenía al 31 de diciembre de 2006. Es decir, en ambos casos, se dejan de considerar los aumentos salariales de 2007 y 2008, así como el aumento en el valor de la UDI en los mismos dos años de 2007 y 2008, a pesar de que el plazo para escoger esta opción materialmente termina el 31 de diciembre de 2008.

17 Aguinaldo de los trabajadores al SERVicio Del Estado. Se CAlcula CON BASE EN EL SALARIO TABULAR. De los artículos 32, 33, 35, 36 (actualmente derogado) y 42 bis de la Ley Federal de los Trabajadores al Servicio del Estado, se desprende que el salario base para calcular el aguinaldo anual que debe pagarse en dos exhibiciones a los burócratas en un monto de cuarenta días de salario es el tabular, donde se compactaron el salario nominal, el sobresueldo y las "compensaciones adicionales por servicios especiales" que eran otorgadas discrecionalmente por el Estado, pues a partir de la reforma de 1984 a dicha Ley se redujeron las prestaciones que integran el salario o sueldo de los burócratas, que antes comprendía cualquier prestación entregada con motivo del servicio prestado. En consecuencia, si el referido artículo 42 bis no señala un salario distinto para el cálculo del aguinaldo, debe estarse al que la propia ley de la materia define en el artículo 32, que es el tabular, conforme al Catálogo General de Puestos del Gobierno Federal, considerado en el Presupuesto de Egresos. 
Otro aspecto regresivo se encuentra en el artículo décimo transitorio que señala en esencia que, a partir de la entrada en vigor de la Ley y hasta el 31 de diciembre de 2009, los trabajadores que hubieran cotizado 30 años o más y las trabajadoras que hubieren cotizado 28 años o más, tendrán derecho a pensión por jubilación equivalente al 100\% del promedio del sueldo básico de su último año de servicio y su percepción comenzará a partir del día siguiente a aquel en que el trabajador hubiese disfrutado el último sueldo antes de causar baja. El anterior precepto parece que es regresivo, en virtud que los trabajadores en activo al 1o. de abril de 2007 con 26 años y tres meses de cotización o más y trabajadoras con 24 años y tres meses de cotización o más; el 100\% del promedio del sueldo básico de su último año de servicio será sobre el sueldo básico definido en la nueva Ley, es decir sobre el sueldo del tabulador regional y no sobre el sueldo presupuestal, la compensación y el sobresueldo como estaba en la Ley anterior (aun cuando en la sentencia de la SCJN se aclaró que se incluirán esos aspectos de sueldo presupuestal, compensación y sobresueldo, recordemos que simplemente se está observando en esta parte, si la norma se muestra regresiva).

En otra parte, el artículo décimo transitorio, fracción I, inciso b); se refiere a la pensión de retiro por edad y tiempo de servicios, cuya tabla, en este caso es similar a la de la Ley anterior, pero la determinación de la cuantía de la pensión se determinará con lo estipulado en la fracción IV del referido artículo. De tal manera que para la pensión de retiro por edad y tiempo de servicios, la afectación para los trabajadores en activo se presenta en la determinación de la cuantía de la pensión y en el promedio que hay que considerar para hacer el cálculo, que en la Ley anterior era el promedio del último año laborado, y ahora, con la nueva Ley, no es así, pues si el trabajador ha cambiado de nivel y/o plaza en los últimos tres años, en cuyo caso, si no tiene más de tres años, se tomará en cuenta el promedio del último año laborado con el anterior nivel y/o plaza; este aspecto finalmente fue también interpretado viendo lo más favorable a los trabajadores, pero esto no resta el carácter regresivo de la norma en función de la intencionalidad de su autor.

El artículo décimo transitorio, fracción I, inciso c), se refiere a los trabajadores que se separen voluntariamente del servicio o que queden privados de trabajo después de los 60 años de edad y que hayan cotizado por un mínimo de diez años al Instituto, quienes tendrán derecho a la 
pensión por cesantía en edad avanzada, cuya tabla de aplicación es la misma que la de la Ley anterior, pero, también con una cuantía de pensión calculada sobre el sueldo del tabulador regional y no sobre el sueldo presupuestal, la compensación y el sobresueldo como estaba en la Ley anterior. Al observar esto, queda en claro que fueron modificadas las condiciones bajo las cuales iniciaron su trabajo al servicio del gobierno federal o de entidades y dependencias del mismo gobierno federal, de los estados de la Federación o de instituciones de educación superior, y que cuando están próximos a satisfacer los requisitos para obtener su pensión, renta vitalicia o jubilación, se les cambia el tiempo que tienen que laborar o se les disminuye la cuantía de la pensión que iban a alcanzar, o ambas cosas a la vez; el aspecto de años de servicio se verá a continuación.

Por otro lado, el artículo décimo transitorio, fracción II, señala que a partir del 1o. de enero de 2010, los trabajadores que hubieren cotizado 30 años o más y las trabajadoras que hubieran cotizado 28 años o más, tendrán derecho a pensión de jubilación con el agregado del requisito de edad que no estaba contemplado en la Ley anterior, conforme a la siguiente tabla:

\begin{tabular}{|l|c|c|}
\hline \multicolumn{1}{|c|}{ Años } & $\begin{array}{c}\text { Edad minima de jubilación } \\
\text { para trabajadores }\end{array}$ & $\begin{array}{c}\text { Edad mínima de jubilación } \\
\text { para trabajadoras }\end{array}$ \\
\hline 2010 y 2011 & 51 & 49 \\
\hline 2012 y 2013 & 52 & 50 \\
\hline 2014 y 2015 & 53 & 51 \\
\hline 2016 y 2017 & 54 & 52 \\
\hline 2018 y 2019 & 55 & 53 \\
\hline 2020 y 2021 & 56 & 54 \\
\hline 2022 y 2023 & 57 & 55 \\
\hline 2024 y 2025 & 58 & 56 \\
\hline 2026 y 2027 & 59 & 57 \\
\hline 2028 en adelante & 60 & 58 \\
\hline
\end{tabular}


Así, la pensión por jubilación dará derecho al pago de una cantidad equivalente al $100 \%$ del sueldo que se define en la fracción IV y su percepción comenzará a partir del día siguiente a aquel en que el trabajador hubiese disfrutado el último sueldo antes de causar baja, esto significa que, según la Ley, la edad mínima para el retiro se irá recorriendo paulatinamente. Esto último es relevante porque puede llegar a representar, en casos específicos, una situación notoriamente regresiva pues el interesado en lo individual, alcanzará la edad para su retiro en fecha posterior a la que originalmente pudo haber tenido programada y en casos concretos, en función de la edad y la salud, el derecho será diferido con perjucios para el trabajador.

De conformidad con la tabla del inciso a) de la fracción II del artículo décimo transitorio, todo trabajador en activo a esta fecha (abril de 2007) que haya ingresado al servicio del Estado con menos de 30 años de edad ( 28 en el caso de mujeres), tiene que trabajar más años de los que la Ley anterior señalaba y en todos estos casos, además de aumentarse los años de servicio, se disminuye la cuantía de la pensión en relación con la que tendrían derecho con la Ley anterior.

Todo lo anterior demuestra que, al menos en la redacción e intencionalidad del legislador no existió consideración a algunos instrumentos internacionales de derechos económicos, sociales y culturales mediante los cuales, los Estados signantes como México, se obligaron a proteger la progresividad y no la regresividad de los derechos sociales, como los analizados, y especialmente es de tenerse presente el artículo 26 de la Convención Americana sobre Derechos Humanos, el artículo 1o. del Protocolo del Salvador y el Artículo 2.1 del Pacto Internacional de Derechos Económicos, Sociales y Culturales que comprometen a los Estados parte a adoptar medidas progresivas para lograr la plena efectividad de los referidos derechos.

\section{LAS SENTENCIAS}

La "nueva" Ley del ISSSTE se combatió por estimarse lesiva, principalmente, de la garantía de irretroactividad en perjuicio de los trabajadores al servicio del Estado que antes contaban con un status preciso, determinado y con grados de certeza acerca de su futuro, especialmente en el ámbito del seguro de retiro o "jubilación". Ese planteamiento de incons- 
titucionalidad vino a significar, más bien, un argumento de violación a la prohibición de regresividad en materia de derechos sociales, considerando que la legislación impugnada se cuestionó porque introdujo un nuevo esquema (estimado menos benéfico) en lo relativo a la pensión de retiro, es decir, en lo que atañe a la regulación de la renta vitalicia del contrato del seguro de retiro de los trabajadores del Estado comúnmente llamado jubilación.

Con el objeto de no extendernos demasiado sobre el contenido de la sentencia, se explicitarán de manera genérica las decisiones adoptadas por el Pleno al resolver los asuntos de mérito.

\section{Pronunciamientos específicos de la sentencia}

La sentencia de amparo en revisión analiza los asuntos como un verdadero "amparo social" pues se realiza un estudio abstracto de la totalidad de la ley impugnada, sobre la base argumentativa de que el asunto tiene una naturaleza próxima a la materia laboral por tratarse de derechos derivados de las disposiciones contenidas en el artículo 123, apartado B, fracción XI de la Constitución; y en estos casos de la materia de trabajo, la suplencia de la queja opera a favor del trabajador aun ante la ausencia de conceptos de violación, de forma parecida a la suplencia en materia penal. Vale apuntar que los quejosos señalaron como acto reclamado la Ley del ISSSTE en su integridad y acreditaron estar sujetos a su régimen por ser trabajadores al servicio del Estado y reclamaron además que desde el inicio de su vigencia, la Ley reclamada sujeta a los trabajadores a un nuevo régimen de seguridad social que es sustancialmente diverso al que regulaba la Ley anterior, específicamente por lo que se refiere al sistema de pensiones, siendo éste su principal motivo de queja; además, los promoventes del amparo, casi por lo general solicitaron que al momento de resolver, en suplencia, se consideraran los argumentos expuestos en las diversas demandas y ello llevó al Pleno a determinar que se hiciera un análisis abstracto de la Ley, considerando en su conjunto las disposiciones que regulan cada uno de los sistemas o mecanismos que comprende el nuevo régimen de seguridad social, tomando como referente los argumentos esgrimidos por la parte quejosa en sus conceptos de violación, así como los hechos valer en diversas demandas de amparo, y no sólo eso, sino que también se tomaron en consideración las argumentaciones 
vertidas en las diferentes comparecencias de trabajadores que la propia Corte recibió en fecha preprogramadas antes de la discusión de los casos.

Los temas generales analizados fueron: a) vicios en el proceso legislativo; b) retroactividad de la ley como sistema; c) delimitación de la garantía de seguridad social; d) estudio de validez constitucional del derecho de opción de los trabajadores; e) interpretación del artículo décimo transitorio; f) estudio sobre las modalidades al anterior sistema de pensiones; g) estudio del nuevo sistema de pensiones que comprende el calor del bono de pensión, el mecanismo del nuevo sistema de pensiones, el estudio sobre la inconstitucionalidad del artículo 251 de la nueva Ley que establece el derecho de los trabajadores a disponer de los recursos acumulados en su cuenta individual a favor del ISSSTE a los diez años de que sean exigibles; h) el estudio de la actuación del Pensionissste; i) el análisis del tema de la posible inconstitucionalidad de lo que puede ser una privatización de la seguridad social en atención a la nueva mecánica de funcionamiento; j) el estudio sobre los seguros, prestaciones y servicios del nuevo régimen de seguridad social; k) la inconstitucionalidad del artículo 25 de la nueva Ley que dispone que en caso de que alguna dependencia o entidad incumpla por más de 12 meses en el entero de las cuotas, aportaciones y descuentos el Instituto podrá suspender a los trabajadores los seguros, prestaciones y servicios que correspondan al adeudo, de manera total o parcial; 1) el estudio de los seguros de riesgos de trabajo e invalidez.

\section{Efectos de las sentencias}

A partir del análisis de los anteriores temas, se concluyó que los efectos de la concesión de amparo que se hizo respecto de diferentes artículos de la Ley del ISSSTE, fueron los siguientes:

Son inconstitucionales los artículos 25, párrafos segundo y tercero, 60, último párrafo, 136, 251 y décimo transitorio, y esta declaración tiene por efecto que las autoridades responsables al aplicar las disposiciones relativas al sistema de pensiones que elija el trabajador, consideren la interpretación que de las mismas realizó el Pleno de la SCJN, aun cuando a partir de dicha interpretación se haya declarado su constitucionalidad, y no apliquen a los quejosos las disposiciones declaradas inconstitucionales, hasta en tanto no sean abrogadas o reformadas. 
Lo anterior se traduce, en lo siguiente:

A. Respecto de los quejosos que expresa o implícitamente opten por mantenerse en el anterior sistema de pensiones modificado

Gozarán de los beneficios relativos al seguro de jubilación, de retiro por edad y tiempo de servicios, invalidez, muerte y cesantía en edad avanzada e indemnización global que prevé el capítulo $\mathrm{V}$ del título segundo de la Ley del ISSSTE de 1983, con las modalidades previstas en los artículos décimo, décimo primero y décimo segundo transitorios de la Ley reclamada, a saber: el otorgamiento de una pensión de jubilación, de retiro por edad y tiempo de servicios, de cesantía en edad avanzada, de invalidez o de muerte cuando se coloquen en el supuesto respectivo y satisfagan los requisitos que más adelante se precisan, conforme a lo siguiente: la cuantía de las pensiones se calculará considerando el promedio del sueldo básico percibido en el último año anterior a la fecha de baja (sueldo regulador); el sueldo base de cotización que se tomará en consideración para el cálculo de la pensión será el previsto en el artículo 17 de la nueva Ley, en la inteligencia de que éste se integra por los mismos conceptos que comprende el sueldo básico previsto en el artículo 15 de la Ley anterior; la cuota mensual máxima de la pensión no podrá exceder del equivalente a diez veces el salario mínimo general mensual del Distrito Federal, misma que se incrementará anualmente con efectos a partir del 1o. de enero de cada año; para el reconocimiento de los periodos mínimos de cotización se considerará uno solo de los empleos, aun cuando el trabajador hubiese desempeñado simultáneamente varios cotizando al Instituto, cualesquiera que fuesen.

En consecuencia, para dicho cómputo se considerará, por una sola vez, el tiempo durante el cual haya tenido o tenga el interesado el carácter de trabajador; los pensionados recibirán además una gratificación anual en igual número de días a las concedidas a los trabajadores en activo según la cuota diaria de su pensión; el otorgamiento de una indemnización global en caso de que el trabajador se separe definitivamente del servicio sin tener derecho a una pensión de jubilación, de retiro por edad y tiempo de servicios, de cesantía en edad avanzada o de invalidez.

En caso de fallecimiento del trabajador, el importe de la referida indemnización se entregará a sus beneficiarios; para tener derecho a una pensión de jubilación, de retiro por edad y tiempo de servicios, de cesan- 
tía en edad avanzada, de invalidez o de muerte, deberán actualizarse los supuestos y satisfacerse los requisitos que se indican a continuación.

1) Pensión por jubilación. Se requiere un periodo mínimo de cotización de 30 años para los hombres y 28 años para las mujeres. A partir del primero de enero de 2010, además del referido periodo mínimo de cotización, se requiere una edad mínima de 51 años para los hombres y 49 años para las mujeres, misma que se incrementará cada dos años hasta el 2028 para llegar a una edad mínima de 60 y 58 años respectivamente. La jubilación da derecho al otorgamiento de una pensión equivalente el $100 \%$ del sueldo regulador y su percepción comenzará a partir del día siguiente a aquel en que el trabajador hubiese disfrutado el último sueldo antes de causar baja.

2) Pensión de retiro por edad y tiempo de servicios. Se requiere un periodo mínimo de cotización de 15 años o más al Instituto y una edad mínima de 55 años, la que a partir del 1o. de enero de 2010 se incrementará cada dos año hasta el 2018 para llegar a una edad mínima de 60 años; el monto mínimo de la pensión es equivalente al 50\% del sueldo regulador, el cual se incrementa gradualmente hasta el $95 \%$ del mismo sueldo de acuerdo con los años de servicio, la percepción de la pensión comenzará a partir del día siguiente a aquel en que el trabajador hubiese disfrutado el último sueldo antes de causar baja.

3) Pensión de cesantía en edad avanzada. Se concede a los trabajadores que se separen voluntariamente del servicio o queden privados de un trabajo, siempre que hayan cotizado un mínimo de 10 años al Instituto y tengan una edad mínima de 60 años, la que a partir del 1o. de enero de 2010 se incrementará cada dos años hasta 2018 para llegar a una edad mínima de 65 años; el monto mínimo de la pensión es equivalente al $40 \%$ del sueldo regulador, el cual se incrementa en $2 \%$ por cada año de edad hasta llegar a la pensión máxima del $50 \%$ del mismo sueldo; el pago de la pensión iniciará al día siguiente en que el trabajador se separe voluntariamente del servicio o quede privado del trabajo.

4) Pensión por invalidez. Se concede a los trabajadores que se inhabiliten física o mentalmente por causas ajenas al desempeño de su cargo o empleo, siempre que hayan cotizado cuando menos 15 años al Instituto; el monto mínimo de la pensión es equivalente al 50\% del sueldo regulador, el cual se incrementa gradualmente hasta el 95\% del mismo sueldo de acuerdo con los años de servicio; la percepción de la pensión comen- 
zará a partir del día siguiente al de la fecha en que el trabajador cause baja motivada por la inhabilitación.

5) Pensión por muerte del trabajador. Tienen derecho a ella los familiares derechohabientes del trabajador fallecido, en el orden establecido en la sección de pensión por causa de muerte del seguro de invalidez y vida que regula la nueva Ley del ISSSTE, siempre que el trabajador haya cotizado al Instituto por un periodo mínimo de 15 años. También tienen derecho a la referida pensión los familiares derechohabientes del pensionado por jubilación, retiro por edad y tiempo de servicios, cesantía en edad avanzada o invalidez; el monto de la pensión será equivalente al $100 \%$ del monto de la pensión que hubiere correspondido al trabajador, o en su caso, de la que gozaba el pensionado. La percepción de la pensión iniciará al día siguiente al de la muerte del trabajador o pensionado; lo anterior sin perjuicio de observar las restantes disposiciones del capítulo V del título segundo de la Ley del ISSSTE de 1983.

\section{B. Otorgamiento de beneficios relativos al seguro de jubilación, de retiro por edad y tiempo de servicios, invalidez, muerte y cesantía en edad avanzada e indemnización global}

Los trabajadores deberán cubrir las cuotas relativas al seguro de retiro, cesantía en edad avanzada y vejez (rcv) y al seguro de invalidez y vida (iv) que regula la nueva Ley. La cuota del seguro de retiro, cesantía en edad avanzada y vejez, al entrar en vigor la Ley reclamada será del 3.5\% del sueldo básico y se irá incrementando paulatinamente hasta llegar al $6.125 \%$ en 2012; las cuotas y aportaciones del seguro de retiro, cesantía en edad avanzada y vejez, se ingresarán a la tesorería del ISSSTE, el que a su vez deberá transferir los recursos relativos a la Secretaría de Hacienda y Crédito Público, en tanto corresponde a dicha dependencia pagar las pensiones de los trabajadores que opten por mantenerse en el anterior sistema de pensiones modificado. Lo anterior, con excepción de la aportación de las dependencias y entidades del $2 \%$ de retiro, la que se destinará a la subcuenta de ahorro para el retiro (SAR) de la cuenta individual del trabajador que deberá ser administrada exclusivamente por el Pensionissste. 


\section{Seguro de riesgo de trabajo}

Tendrán derecho a una pensión en términos de lo dispuesto para el seguro de riesgos de trabajo que prevé la nueva Ley del ISSSTE, para lo cual, el gobierno federal deberá transferir al Instituto los recursos necesarios para la contratación de un seguro de pensión a favor del trabajador, o en caso de fallecimiento, del seguro de sobrevivencia para sus familiares derechohabientes.

Por cuanto se refiere a las restantes prestaciones de seguridad social (seguro de salud, sistema integral de crédito y servicios sociales y culturales), así como en lo relativo al financiamiento de todos los seguros y prestaciones, transferencia de derechos y demás aspectos generales del régimen de seguridad social, quedarán sujetos a las disposiciones de la nueva Ley del ISSSTE.

\section{Respecto de los quejosos que expresamente opten por migrar al nuevo sistema de cuentas individuales}

Tanto ellos como sus familiares derechohabientes tendrán derecho a gozar de los beneficios del régimen de seguridad social en términos de lo previsto en la nueva Ley del ISSSTE, con las siguientes salvedades: 1) No se les podrán suspender los seguros, prestaciones y servicios por incumplimiento de las dependencias y entidades para las que laboran en el entero de las cuotas, aportaciones y descuentos. 2) Tratándose de riesgos de trabajo, la procedencia de la solicitud de su calificación y su reconocimiento, no se condicionará a que éste se haya notificado al Instituto por la dependencia o entidad para la cual laboran los quejosos o por sus familiares dentro de los tres días siguientes al en que se haya tenido conocimiento del mismo. 3) Para el otorgamiento de la pensión de viudez no resultan aplicables las limitaciones consistentes en que el trabajador fallezca antes de cumplir seis meses de matrimonio, o bien, que al contraer matrimonio tenga más de 55 años de edad o estuviere percibiendo una pensión de riesgos de trabajo o invalidez y fallezca antes de que transcurra un año a partir de su celebración. 4) No opera la prescripción del derecho a disponer de los recursos acumulados en su cuenta individual a favor del Instituto. Las salvedades antes precisadas también deberán observarse tratándose de los quejosos que opten por mantenerse en el anterior sistema de pensiones modificado. 
Para los efectos antes precisados, las autoridades responsables deberán dictar las medidas que sean necesarias a efecto de que todas las autoridades que con motivo de sus funciones se encuentren vinculadas al cumplimiento del fallo protector, tengan conocimiento del alcance de sus efectos $\mathrm{y}$ de las personas amparadas por el mismo.

\section{EL VOTO DE MINORÍA}

Los ministros Juan N. Silva Meza y Guillermo I. Ortiz Mayagoitia elaboraron un voto de minoría en el que se reconoce de manera expresa, por primera vez, la prohibición constitucional de regresividad de los derechos sociales.

Para los ministros de la minoría, la nueva Ley del ISSSTE es regresiva cuando menos en tres aspectos esenciales: 1) hay un aumento de cuotas a los trabajadores en activo, y aumento de edad y de años de servicio; 2) hay un cambio del sistema de pensiones por la cuenta individual para los trabajadores en activo, los cuales pueden optar entre la cuenta individual que establece la nueva Ley, o la reducción, es decir, someterse a un régimen que establece el artículo décimo transitorio, que tiene como consecuencia la reducción de pensiones obligatorias a las que opcionalmente pueden acceder los actuales trabajadores en activo en dos aspectos: primero, el año de pensiones es año natural, está calculado en doce meses, contra trece meses que da actualmente el ISSSTE, porque se paga un año de aguinaldo, ya no aparece previsto el mes de aguinaldo, y segundo, no se incrementa la pensión que se obtiene en términos del artículo décimo transitorio de la Ley, la pensión que se alcance queda, por así decirlo congelada, ya que no está previsto ningún mecanismo de actualización (además, tratándose del régimen aplicable al seguro de riesgos de trabajo, tal como lo precisa la fracción $\mathrm{V}$ de ese precepto transitorio, los trabajadores necesariamente deberán sujetarse al sistema de cuentas individuales, con la incertidumbre sobre la naturaleza de la relación entre el asegurado y la aseguradora); 3) existe la intención de poner límite a la responsabilidad del Estado en materia de pensiones. ${ }^{18}$

18 Así, conforme al nuevo sistema al que se sujeta a los trabajadores que lo elijan, cuando estén en condiciones de retirarse, se les entregarán fondos para que compren/adquieran de una empresa del sistema financiero nacional, de una aseguradora, adquieran la pensión de retiro, y a diferencia de lo que sucede con el Instituto de Seguridad y Servi- 
En el voto de minoría, se subraya que esos cambios al régimen de seguridad social son inconstitucionales, por afectar de manera retroactiva los derechos adquiridos por los trabajadores al régimen de seguridad social como tal. ${ }^{19}$ A ese respecto, la minoría opinó que los derechos sociales son indisponibles para el legislador, en tanto que están constituidos como garantías y/o bases mínimas de seguridad social por el artículo 123 , apartado B, fracción XI, de la norma suprema. ${ }^{20}$ Se estima que, si bien el legislador tiene posibilidades de configuración, restructuración o actualización, ello nunca debe realizarse rebasando esas bases mínimas.

Para los ministros de la minoría:

la base de los derechos públicos subjetivos mínimos de seguridad social para los trabajadores del Estado, se deriva del artículo 123 de la Constitución federal, en función de la caracterización del salario y la vinculación de éste con las prestaciones sociales que le son inherentes, para determinar cómo efectivamente constituyen un derecho adquirido, respecto de los cuales existe una barrera infranqueable como límite para que ni el legislador ordinario ni ninguna otra autoridad, puedan afectar esos derechos fundamentales a gozar de un salario y de las prestaciones que de él deriven, sin que ello implique la transgresión flagrante a la protección constitucional.

cios Sociales de los Trabajadores del Estado, respecto al que se prevé que cuando sus fondos sean insuficientes, el Estado hará las aportaciones conducentes; en el nuevo régimen de cuentas individuales, la Ley no establece ese supuesto, esto es, ante la insuficiencia de los fondos necesarios para cubrir las pensiones, quién deberá hacerse cargo de la contingencia financiera.

19 "La nueva Ley del ISSSTE adolece del vicio de retroactividad para los trabajadores en activo, ¿por qué?, porque se les saca de él aunque se establece una opción, la opción no es que se quedaran como estaban o ir a nuevo régimen sino ir a dos nuevas posibilidades que son diferentes: una, contrastantemente diferente con el régimen actual, otra se dice, se asemeja mucho al régimen actual, pero aun asemejándose mucho al régimen actual imprime modalidades muy importantes que desde nuestro punto de vista afectan derechos adquiridos".

20 Para mayor claridad, es pertinente precisar que al establecer el artículo 123, apartado B, fracción XI, de la Constitución Política de los Estados Unidos Mexicanos, que: "La seguridad social se organizará conforme a las siguientes bases mínimas...", se están otorgando a favor de los trabajadores una serie de derechos, que son definitivamente adquiridos, y no meras expectativas de derecho, hacemos notar tal situación, porque el Constituyente estableció "bases mínimas" dentro del marco organizativo de la seguridad social, por lo tanto, es claro que la misma hace referencia a un conjunto integrado por derechos constitucionales adquiridos e indisponibles para el legislador ordinario. 
Para la minoría, el hecho de que la Ley del ISSSTE imponga otras modalidades, otras cargas, otros tiempos, implica alterar esos derechos indiscutiblemente adquiridos, lo que genera que el nuevo sistema integral de seguridad social resulte inconstitucional, no sólo bajo los estándares de los argumentos mencionados, sino que también es evidente su incompatibilidad con nuestro régimen constitucional a la luz de los principios de legalidad, seguridad jurídica, no retroactividad, "así como del principio de no regresividad", máxime que el artículo 2o. del Pacto sobre Derechos Económicos, Sociales y Culturales identifica la obligación del Estado parte de asegurar el "logro progresivo" de ese tipo de derechos.

Los ministros Ortiz y Silva explican que el Estado viola esa disposición internacional si tolera o causa "regresión" en el disfrute de uno o varios derechos sociales, de lo cual deriva que

aun en situaciones de escasos recursos, o un mal funcionamiento de las instituciones de seguridad social, el Estado debe hacer esfuerzos, inclusive a través de la cooperación internacional, para avanzar $-\mathrm{y}$ no derogar o menguar cómo ocurre en este caso- el disfrute de derechos como las pensiones por jubilación y vejez, incluyendo el arrendamiento de vivienda adecuada y sus elementos constitutivos así como toda aquella disminución de los derechos constitucionales en el marco organizativo del sistema de seguridad social.

Para la minoría, la prohibición de regresión en materia de derechos sociales, a diferencia de la postura sostenida por la mayoría de los ministros, genera derechos adquiridos, lo que ha sido reafirmado en los Principios sobre la Implementación del Pacto Internacional sobre Derechos Económicos, Sociales y Culturales (1986) y los Lineamientos Maastricht (1997), así como múltiples casos de jurisprudencia internacional a través de las funciones de monitoreo del Comité de Derechos Económicos Sociales y Culturales. Con esa base, en el voto se considera que:

una vez alcanzado cierto nivel de protección constitucional y legal — como manifiestamente lo alcanza el artículo 123, apartado B, de la Constitución federal y la anterior Ley del Instituto de Seguridad y Servicios Sociales de los Trabajadores del Estado.- - la libertad de configuración del legislador en materia de derechos sociales se ve restringida. 
En ese orden de ideas, en el voto se justifica la prohibición de regresividad mediante razones de eficiencia: en primer lugar, el respeto a los derechos adquiridos inhibe la deserción del sistema de pensiones. Al contrario, no respetarlos lleva necesariamente a problemas de elusión y evasión de las contribuciones a la seguridad social. En segundo lugar, el respeto a esta clase de derechos, incentiva la formalización del trabajo. Y en último lugar, el respeto a los derechos adquiridos, al inhibir la deserción, también minimiza el riesgo de indigencia de la población protegida, destacando que los ejemplos de reformas en los sistemas de seguridad social de la era de la globalización demuestran cómo el retiro del Estado de sus obligaciones de cumplir los derechos económicos sociales y culturales puede llevar a la privación de los mismos.

Los ministros de la minoría terminan señalando que:

Somos partidarios de contar con un sistema de seguridad social moderno, de lo que no lo somos es de que desaparezcan o mengüen considerablemente los derechos de los trabajadores existentes previamente, máxime que su consagración deviene de la ley fundamental. En esa tesitura el artículo 123 apartado B, fracción XI, inciso a), constitucional impone a los poderes públicos la obligación indelegable de establecer y mantener un sistema protector que se corresponda con las características técnicas de los mecanismos de cobertura propios de un sistema organizacional de seguridad social, en otras palabras dicho artículo consagra en forma de garantía institucional un régimen público cuya preservación es indispensable para asegurar los principios constitucionales configurando, tal y como hemos mencionado, un núcleo indisponible para el legislador.

\section{CONCLUSIONES}

Al parecer, la opinión minoritaria resulta persuasiva. Es muy dudoso que la nueva Ley del ISSSTE sea constitucional en la parte que disminuye beneficios de seguridad social y/o establece mayores cargas a los trabajadores para obtenerlos en comparación con la Ley anterior. Cualquier decisión (federal local o municipal, y por cualquier poder u órgano autónomo) que incida sobre los derechos sociales debería ser adoptada en términos óptimos sobre una base de reflexiones necesariamente basadas en un sentido de responsabilidad estatal frente al grupo social protegido por la norma social, en obvio que las decisiones de una norma de progreso, 
válidamente no puede tener pasos regresivos, a menos que éstos representen la única alternativa consecuencial posible para conservar el mayor grado de protección del derecho social y evitar con ello (y sólo así) situaciones extintivas. Es decir, un paso regresivo solamente puede encontrarse válidamente motivado a manera de una ultima ratio con características tales que represente la única alternativa real y materialmente posible para proteger al grupo identificado por la propia norma social; además, por el alto contenido democrático que lógicamente caracteriza a todos los derechos sociales, esas razones últimas, deben ser del conocimiento, al menos evidente o inobjetable por los sujetos destinatarios del derecho social.

Resulta también cuestionable que la Ley pueda justificarse, sin más, aduciendo la existencia de razones relacionadas con la viabilidad financiera del sistema de seguridad social, pues, como se ha dicho en este trabajo, una ley regresiva determina una presunción de invalidez, transfiriendo al Estado la carga de argumentar no sólo la existencia de un interés estatal permisible e imperioso, sino también la ausencia de cursos de acción alternativos que sean menos restrictivos de los derechos sociales implicados.

Las pensiones de los trabajadores no son "dadivas" ni "gracias" que el gobierno otorga discrecionalmente a los trabajadores, más bien se conforman de retenciones que se hacen al salario de los trabajadores (artículos 6o. y 21 LISSSTE). Las prestaciones constitucionales mínimas de seguridad social son producto del trabajo y, por regla general, forman parte del salario del trabajador.

Por otro lado, el goce del salario se considera un derecho humano inviolable que, por sus características y desde una perspectiva tanto material como formal, debería tener un mayor peso frente a cualquier determinación de carácter político. Teniendo en cuenta esta premisa, la conclusión sería que el Estado se encontrara imposibilitado para afectar injustificadamente, tanto el salario del trabajador como las prestaciones mínimas de seguridad social que son derivadas del producto del trabajo; de esta manera, cuando el Estado afecta los derechos humanos de los trabajadores ello tiende a repercutir otras garantías individuales, como la propiedad privada, la libertad contractual, la igualdad, la integridad física y síquica, la dignidad, la educación, la salud, la vivienda, los alimentos, la familia, la participación democrática efectiva e informada del trabajador, etcétera. 
Las pensiones, por las características que históricamente han presentado y que se les han reconocido, parece que pueden llegar a ser consideradas una especie de salario diferido del trabajador, como algo que se parece a un fruto del ahorro forzoso que realizó durante toda su vida laboral que, por esa concepción, lo lógico sería que dichos ahorros se le devolvieran cuando ello fue legalmente pactado, pues lo contrario implicaría una confiscación.

Como la nueva Ley del ISSSTE dispuso - o al menos incidió- sobre todos esos derechos de los trabajadores, y como los mismos son base para sus proyectos de vida, es claro que dicha norma, por sus características restrictivas y unilaterales, afectó crucialmente a dichos individuos en su esfera de autonomía personal que, por sus características personalísimas, liberales y hasta íntimas, razonablemente sólo podrían ser de su propia incumbencia; siendo que, jurídicamente, no puede aceptarse que la libertad decisoria de los trabajadores haya sido desplazada normativamente por una intrusión del Estado.

Ahora bien, en relación con la sostenibilidad financiera del sistema de seguridad social, podría pensarse que el Estado no debe tener la carga de soportar el financiamiento de un sistema previsto para un grupo específico de ciudadanos con recursos públicos derivados de la recaudación general; sin embargo, dicha cuestión en el caso de México, parece debatible, pues la sostenibilidad financiera se pretendió solucionar con un cambio de esquema y, con respecto a éste, no existe certeza ni prueba contundente de que las medidas estaduales adoptadas en el contenido de la nueva Ley referida sean, no sólo la última, sino la única vía de solución a la problemática de sostenibilidad.

La solución que se contiene en la nueva normatividad, bajo las anteriores reflexiones parece que no resultaría absolutamente aceptable; debiendo destacarse que la norma constitucional no ordena la autosostenibilidad del sistema de seguridad social, sino únicamente su sostenibilidad, máxime que aquél — por disposición constitucional— es de utilidad pública e implica la satisfacción efectiva de derechos fundamentales de los trabajadores.

Un sistema se vuelve insostenible cuando el aporte del Estado es inferior al que se necesitaría para cubrir el déficit que se haya creado. La Constitución no señala un límite al gasto social, ello implica que puede existir un cierto margen de libertad política del Congreso de la República 
para determinar cuál es el nivel de gasto apropiado; si el Congreso determinara que el presupuesto óptimo a destinar al sistema fuera igual al saldo financiero, entonces, por definición, el sistema sería sostenible, de lo cual deriva que es la decisión política la que otorga o no la viabilidad financiera a los sistemas de seguridad social, lo cual se traduce en que el juego político determina si existe o no viabilidad financiera, con los riesgos o beneficios que ello conlleva.

El hecho de que el legislador, a través de la nueva Ley del ISSSTE, materialmente y en cierto grado haya trasladado a los trabajadores el déficit financiero del sistema parece poco justificable, y más aún si se toma en cuenta que esa inviabilidad es imputable al propio Estado (a través del organismo descentralizado), al parecer debido a su inadecuada previsión, manejo y administración; en otras palabras, la creación de una ley regresiva supone generar un esfuerzo injustificado para los cotizantes de la actual generación, dejando de lado los criterios de solidaridad que caracterizan a la seguridad social, pasando inadvertido que la generación actual prácticamente estaría pagando la deuda vinculada con situaciones del pasado, además de los costos propios, cuando por virtud de esta transgeneracionalidad lo óptimo fuera que la carga recayera en instituciones que se caracterizan por su permanencia.

Ahora bien, parece ser que no todo en la Ley ni en la sentencia es negativo, por el contrario, en ambos elementos objetivamente existen muchos aspectos positivos, como son los pronunciamientos sobre la protección de los derechos sociales, principalmente, contenidos en el análisis abstracto de toda la legislación impugnada con base en la suplencia de la queja, las interpretaciones conforme a la Constitución en beneficio de los trabajadores (enunciadas una a una en este estudio), los novedosos pronunciamientos jurisdiccionales contenidos no sólo en las versiones taquigráficas, votos particulares e intervenciones de algunos ministros, sino incluso en las ejecutorias y que se refieren a la progresividad y no regresividad de los derechos sociales, lo cual constituye un avance en materia constitucional.

Sin embargo, contrariamente a la intención de los creadores de la nueva Ley del ISSSTE, creemos que incluso las decisiones políticas financieras y económicas de los poderes constituidos tienen como límite los derechos humanos de los individuos. 